\title{
GranaBook: a construção da informação em um ter- ritório midiatizado
}

\section{GranaBook: building information in a mediatized territory}

\author{
Rejane de Oliveira Pozobon ${ }^{[a]}{ }^{\text {Andressa Dembogurski Ribeiro }}{ }^{[b]}$ \\ [a] Jornalista e Relações Públicas, Professora do Programa de Pós-Graduação em Comunica- \\ ção da Universidade Federal de Santa Maria, RS, e-mail: rejanepozobon@gmail.com \\ ${ }^{[b]}$ Publicitária, mestranda, bolsista CAPES do Programa de Pós-Graduação em Comunicação \\ da Universidade Federal de Santa Maria, RS, e-mail: andressadembo@gmail.com
}

\section{Resumo}

A configuração da sociedade midiatizada faz com que os processos de comunicação caminhem em uma direção em que as tecnologias permitem um novo entendimento dos processos midiáticos. A possibilidade da migração dos conteúdos comunicacionais para outras ambiências faz com que aconteçam procedimentos de desterritorialização e reterritorialização. Para entendermos essas mudanças ocorridas nos últimos tempos e o que isso significa para a sociedade, propomos um estudo dos conceitos de territorialização, desterritorializa- 
ção e reterritorialização, trazidos por diferentes áreas do conhecimento, e baseados nos pensamentos de Lemos (2005), Santos (2006), Corrêa (2006) e Andrade (2002). Procuramos relacionar os ensinamentos trazidos pelos autores citados com os pensadores do campo da comunicação. Para isto, também faremos uma breve exposição do conceito de midiatização. Por fim, traremos como exemplo a construção do GranaBook, o primeiro guia financeiro colaborativo feito através de interação de usuários da página do Itaú Universitários na rede social digital Facebook.

Palavras-chave: Territorialização. Desterritorialização. Reterritorialização. GranaBook.

\begin{abstract}
Setting the mediatic society makes communication processes to walk in a direction in which technologies enable a new understanding of media processes. The possibility of migration of communicational contents to other ambiance makes happen deterritorialization and reterritorialization procedures. To understand these changes in recent times and what it means for society, we propose a study on the concepts of territorialization, deterritorialization and reterritorialization brought from different areas of knowledge and based on the thoughts of Lemos (2005), Santos (2006), Correa (2006) and Andrade (2002). We relate the teachings brought by the authors cited with the thinkers in the field of communication. For this, we will also make a brief exposition of the concept of mediatization. Finally, we will bring the example of the GranaBook, the first collaborative financial guide developed through interaction of users of the Itaú Universitários page on the Facebook digital social network.
\end{abstract}

Keywords: Territorialization. Deterritorialization. Reterritorialization. GranaBook.

\title{
Considerações Iniciais
}

O presente artigo se propõe a discutir as formas de comunicação e de construção de informação advindas da evolução tecnológica. O surgimento de territórios de conhecimento, de relacionamento e de difusão de conteúdo também são pontos chaves deste estudo. Para isto, ele está dividido em duas partes. Os conceitos de territorialização, desterritorialização e reterritorialização são os norteadores deste estudo e estão presentes na primeira parte do artigo. Estes servem de base para se entender como se dá a questão dos espaços midiáticos digitais e as práticas comunicacionais possibilitadas por eles. Na segunda parte, utiliza-se o GranaBook ${ }^{1}$, o primeiro guia colaborativo construído pela Internet, para exemplificar os proces-

Guia financeiro colaborativo do Banco Itaú. www.granabook.com.br

Rev. Estud. Comun., Curitiba, v. 15, n. 37, p. 171-184, maio/ago. 2014 
sos de territorialização, desterritorialização e reterritorialização, fazendo uma comparação das diferentes ambiências em que o guia poderia ter sido construído.

Com o passar do tempo e o progresso das tecnologias, a comunicação deixou de ser centralizada, vertical e unidirecional e passou a ocorrer com interatividade e multimidialismo, fato que permite referirmos a essas tecnologias como pósmidiáticas (SODRÉ, 2002). Esse processo de avanços e mudanças nas mídias e consequentemente em alguns aspectos da vida humana foi intitulado como midiatização. A mídia está acoplada na vida do ser humano de tal forma que já não é possível perceber a sociedade separada dos usos midiáticos. Sodré (2002) acredita que já é lugar-comum afirmar que o desenvolvimento dos sistemas e das redes de comunicação transforma radicalmente a vida do homem contemporâneo, tanto nas relações de trabalho como nas de sociabilização e lazer.

O desenvolvimento e a intensificação das convergências tecnológicas (informática, tele comunicações e meios audiovisuais) produziram a formação, organização e efeitos nos processos de interação social, nomeados como novas "formas tecnológicas de vida". Esses processos, também entendidos como midiatização da sociedade, afetam os campos sociais, suas práticas e suas interações, pois passam a se organizar e a funcionar tendo como referência a existência da cultura, de lógicas e operações midiáticas (FAUSTO NETO, 2008).

É também neste sentido que Hjavard (2012) comenta sobre o global e o local. Os meios de comunicação encurtaram as fronteiras e possibilitam as pessoas estar em diversos lugares ao mesmo tempo, “[...] os meios de comunicação, expandem nosso contato com os eventos e fenômenos no que, outrora, eram lugares distantes" (HJAVARD, 2012, p.62). As tecnologias que facilitam o ato de comunicar fazem parte da midiatização como outra forma de emitir e receber mensagens, em que a interatividade e instantaneidade estão presentes.

Como os meios de comunicação - e em particular, os digitais - tornaram-se integrados às rotinas de outras instituições, os usuários também se tornaram produtores de conteúdo. O principal serviço das novas mídias é produzir relações sociais entre as pessoas, e os usuários são cada vez mais estimulados a gerar o conteúdo por si próprios. Dessa forma, os meios de comunicação contemporâneos são orientados por uma lógica de duas faces: profissionalismo e o conteúdo gerado por usuários (HJAVARD, 2012, p.74).

Os meios de comunicação digitais mudaram a forma de produzir e consumir conteúdo midiático e tornaram possível a participação dos usuários. Hjavard (2012) acredita que, com os meios digitais, as culturas se aproximam e nenhuma é capaz de ser construída de forma isolada da outra. Estas ambiências digitais acresceram 
novos territórios que se desterritorializaram do seu ambiente de origem e se reteritorializaram com características específicas deste meio.

Abordam-se, então, a seguir, os conceitos de territorialização, desterritorialização e reterritorialização, e logo após, o exemplo do GranaBook para que se entenda suas aplicações no ambiente midiatizado.

\section{Territorialização, desterritorialização e reterritorialização}

Territorialização, desterritorialização e reterritorialização são conceitos utilizados não só na geografia, mas também na comunicação, sociologia, psicologia, etc. Alguns autores utilizam como sinônimos os termos território e espaço, o que também é feito neste estudo.

As expressões território, territorialidade e desterritorilidade têm uso antigo nas Ciências Sociais e naturais. Nas ciências naturais, o território é área de influência e dominação de uma espécie animal que nele exerce o domínio. Já nas Ciências Sociais, a expressão território é muito utilizada, desde o século passado, por geógrafos como Frederico Ratzel e Elisée Reclus (ANDRADE, 2002).

O significado de território pode estar ligado, além do pertencimento da "terra", às questões identitárias de um determinado povo ou cultura. Lemos (2005) acredita que a noção de território é polissêmica, e não deve ser entendida apenas como espaço físico delimitado. Ele define território por meio da ideia de controle sobre fronteiras, podendo elas serem físicas, sociais, simbólicas, culturais, subjetivas. Para o autor, criar um território é controlar processos que se dão no interior dessas fronteiras. Já desterritorializar é se movimentar nessas fronteiras, criar linhas de fuga, re-significar o inscrito e o instituído. A vida social para ele precisa de "territórios" para existir (leis, instituições, arquiteturas), mas o vitalismo só existe a partir de tensões desterritorializantes que impulsionam e reorganizam esses "territórios". A vida social deve ser entendida como mobilidade e fluidez e não como arquitetura fechada (poder, classe, instituições). "A dinâmica da sociedade se estabelece mais por movimentos de fuga do que por uma essência imutável das coisas. O que interessa são processos, dinâmicas des-re-territorializantes que marcam o social" (LEMOS, 2005, p.4).

A noção de espaço como um conjunto indissociável de sistemas de objetivo e sistemas de ações é dada por Santos (2006), e ele reconhece categorias analíticas internas deste espaço. "Entre elas, estão a paisagem, a configuração territorial, a divisão territorial do trabalho, o espaço produzido ou produtivo, as rugosidades e as formas de conteúdo." (SANTOS, 2006, p. 12) . O pensamento deste autor (2006) vai ao encontro do de Lemos (2005) quando acredita que existam processos de desterritorialização, e que eles acontecem quando os elementos fixos permitem

Rev. Estud. Comun., Curitiba, v. 15, n. 37, p. 171-184, maio/ago. 2014 
ações que modificam o próprio lugar, fluxos novos ou renovados recriam as condições ambientais e as condições sociais, e redefinem cada lugar. Para Santos (2006), "esses fluxos são resultado direto ou indireto das ações e atravessam ou se instalam nos fixos, modificando a sua significação e o seu valor, ao mesmo tempo em que, também se modificam" (SANTOS, 2006, p. 38).

Quando um território deixa de existir, seja por mudanças culturais, sociais ou até mesmo geográficas, acontece o processo de desterritorialização, que, para Corrêa (2002), é entendida como a perda do território apropriado e vivido. Novas territorialidades ou re-territorialidades, dizem respeito à "criação de novos territórios, seja através da reconstrução parcial, de velhos territórios, seja por meio da recriação parcial, em outros lugares, de um território novo que contém, entretanto, parcela das características do velho território" (CORRÊA, 2002, p. 252).

Como já comentado, o território pode ser determinado pelas identidades sociais existentes nele. Para Sodré (apud BARICHELLO, 2001), a ideia de território é tida quanto à questão da identidade, pois ela demarca um espaço em relação aos outros. O território marca limites, especifica o lugar em que acontecerá a ação do sujeito.

[...] podemos falar de uma dimensão territorial ou de uma 'lógica do lugar', de uma cultura, quando o espaço não se constitui em dado autônomo mas em vetor com efeitos próprios, capaz de afetar as condições das ações humanas. Pensar em territorialização é admitir a heterogeneidade dos espaços, a ambivalência dos lugares e, desse modo, acolher os movimentos de diferenciação, a indeterminação, o paradoxo quanto à percepção do real - em suma- a infinita pluralidade do sujeito (SODRÉ apud BARICHELLO, 2001, p. 105).

As infinitas pluralidades do sujeito (SODRÉ apud BARICHELLO, 2001) podem ser percebidas quando Andrade (2002) comenta que "[...] a formação de um território dá às pessoas que nele habitam a consciência de sua participação, provocando o sentimento da territorialidade que, de forma subjetiva, cria uma consciência de confraternização entre as mesmas" (ANDRADE, 2002, p.214). Neste sentindo, pode-se entender porque o conceito de território deixa de ser restrito à geografia e perpassa por diversas áreas da vida humana.

A identidade territorial não diz respeito apenas à geografia. Diz respeito também aos lugares e posições nas instituições, castas, hierarquias, ordens, disciplinas, tudo o que organiza um espaço por meio de fronteiras, escalas e níveis. [...] O Espaço das mercadorias desterritorializa, desestrutura os âmbitos anteriores da sociabilidade e da identidade. Os indivíduos são redefinidos por seu papel na fabricação, na circulação e no consumo de coisas, informações e imagens (LÉVY, 1994, p. 132). 
A mudança social ocorrida com o surgimento da eletricidade, por exemplo, alterou as formas de viver do homem (comunicação, locomoção, informação, etc.), e a análise territorial desempenha importante papel na compreensão da mudança social de um modo geral, pois a mudança social é em parte isso, a vida e a morte dos territórios. A partir do momento em que são inclusas novas formas de viver, isso pode acontecer pelo surgimento de uma nova forma de comunicação, como citado acima, inicia-se o processo de desterritorialização para depois reterritorializarmos o antigo território.

No entanto, a dinâmica territorializante da sociedade moderna cresce junto como novos fenômenos desterritorializantes, engendrados pelas mídias de massa, pelas revoluções sociais, pela flutuação das fronteiras culturais e subjetivas. Começam a emergir movimentos de compressão do espaço-tempo e de desencaixe que se concretizam na era pós-industrial (LEMOS, 2005, p.5).

Geiger (2002) acredita que neste sentido a pós-modernidade, com sua ação de reunir em um mesmo local objetos trazidos de diversos lugares e de diversos tempos, possibilita que ocorra a des-territorialização. Como o mundo está em constante transformação, Santos (2006) acredita que não existe um espaço global, mas, apenas, espaços da globalização. O mundo se dá, sobretudo, como norma em diversos pontos dos seus valores técnicos, informacionais, econômicos, sociais políticos e culturais. São ações 'desterritorializadas', separando, geograficamente, a causa eficiente e o efeito final. O território para ele termina por ser a grande mediação entre o mundo e a sociedade nacional e local.

Com a diversidade dos espaços globalizados e a possibilidade de se utilizar espaço-tempo de uma forma rápida e dinâmica é que lanni (apud Souza, 2002, p. 23) acredita que o "[...] desenraizamento que acompanha a formação e o funcionamento da sociedade global põe uns e outros situados em diferentes lugares e distintas condições sócio-culturais, diante de novas, desconhecidas e surpreendentes formas e fórmulas, possibilidades e perspectivas".

Ligado às transformações tecnológicas, a possibilidade de estar em diferentes partes do mundo ao mesmo tempo por meio de um computador conectado à Internet, por exemplo, traz outra forma de se vivenciar o espaço e o tempo. Nicolas (2002) comenta sobre a apropriação desse espaço-tempo pela sociedade. Para ele, quando um grupo social se apropria de um determinado espaço, não só o transforma num espaço social que exprime essa sociedade particular, como constrói um espaço-tempo que é diferente daquele que outra sociedade teria construído.

Nas sociedades modernas as relações sociais são deslocadas dos contextos territoriais de interação e se reestruturam por meio de extensões indefinidas de

Rev. Estud. Comun., Curitiba, v. 15, n. 37, p. 171-184, maio/ago. 2014 
tempo-espaço. Os homens se desterritorializam, favorecendo uma organização racional de suas vidas. Evidentemente uma mudança dessa natureza só pode se concretizar no seio de uma sociedade cujo sistema técnico permite um controle do espaço e do tempo (ORTIZ, 2000, p. 45).

Historicamente uma civilização se limitava a uma área geográfica determinada. "Uma cultura mundializada corresponde a uma civilização cuja territorialidade se globalizou. [...] Ciência, tecnologia e consumo são vetores importantes no processo de formação de uma sociedade globalizada" (ORTIZ, 2000, p. 31-32). A possibilidade de aproximação das localidades também mudou a forma de relacionamento social e a globalização pode assim ser definida como "a intensificação das relações sociais em escala mundial, que ligam localidades distantes de tal maneira que os acontecimentos locais são modelados por eventos ocorrendo muitas milhas de distância e vice-versa" (GIDDENS, 1991, p. 69).

Toda essa contextualização da globalização nas formas de viver e pensar o espaço-tempo se dá em maior parte pelo surgimento de técnicas que tornaram esta proximidade possível. Essas tecnologias possibilitam a vivência do ser humano em determinados territórios, onde ele também tem a permissão de se desterritorializar e caso queira se reterritorializar. Por meio deste conteúdo técnico, é possível perceber a evolução ocorrida nos meios de comunicação. A mudança se dá também na forma de relação entre meio e homem. Segundo Barichello (2001), os novos meios de comunicação estão redefinindo os territórios, pois por meio deles, pode-se pensar em territórios flexíveis, sem raízes. Já Santos (2006) pensa que as redes integram e desintegram, destroem velhos recortes espaciais e criam outros.

Toda mídia, da escrita à internet, cria processos que nos permitem driblar os constrangimentos do espaço e do tempo: envio de mensagens à distância, processos mnemônicos. As mídias contemporâneas instauram processos de territorialização e desterritorialização. [...] A compressão do espaço-tempo institui o "tempo real" e a possibilidade de acesso a informações em todos os espaços do globo. $O$ desencaixe nos permite vivenciar processos globais não enraizados na nossa tradição cultural. As mídias eletrônicas criam assim processos desterritorializantes em níveis político, econômico, social, cultural e subjetivo (LEMOS, 2005, p. 3).

Além da evolução dos meios de comunicação de massa, presencia-se o surgimento do computador e depois da Internet, esse meio de comunicação digital trouxe muitas mudanças para o cotidiano social. Lemos (2005) acredita que o ciberespaço é efetivamente desterritorializante, mas essa dinâmica não existe sem novas reterritorializações. Para eles, os processos de des-re-territorializações constituem o homem enquanto ser "aberto ao mundo". Refletindo que o processo de 
desterritorialização é positivo no sentido que acrescenta algo ao antigo território, Deleuze e Guatari (1995) pensam

[...] a desterritorialização como uma potência perfeitamente positiva, que possui seus graus e seus limiares (epistratos) e que é sempre relativa, tendo um reverso, uma complementariedade na reterritorialização. Um organismo desterritorializado em relação ao exterior se reterritorializa necessariamente nos meios anteriores. Tal fragmento, supostamente de embrião, se desterritorializa mudando de limiar ou de gradiente, mas é de novo afetado no novo ambiente. As territorialidades são, pois, atravessadas, de um lado a outro, por linhas de fuga que dão prova da presença, nelas, de movimentos de desterritorialização e reterritorialização (DELEUZE; GUATTARI, 1995, p. 71).

As funções disponibilizadas pela Internet, como a facilidade em criar novas formas de cultura e comunicação, faz com que ela se torne um local propício para a desterritorialização e reterritorialização. A Internet é, efetivamente, máquina desterritorializante sob os aspectos políticos, econômicos, culturais e subjetivos. O ciberespaço cria linhas de fuga e desterritorializações, mas também reterritorializações. Não se deve compreender o ciberespaço como um espaço liso, ou apenas como um espaço de desencaixe e de compressão espaço-tempo, mas como lugar de quebra e criação de controle e de hierarquias, de territorialização e desterritorializações (LEMOS, 2005). “O ciberespaço nasce como espaço estriado, território controlado pelo poder militar e industrial e vai sendo, pouco a pouco, des-reterritorializado por novos agenciamentos da sociedade (tensões de controle e acesso informacionais)" (LEMOS, 2005, p.7).

Um fator relevante neste contexto cibernético é a informação, que por meio da Internet tornou-se acelerada, compartilhada e sem fronteiras. Lévy (1994) comenta sobre as formas de informação:

No Espaço das mercadorias, o sujeito do saber é o complexo militar, industrial, midiático e universitário que de agora em diante chamamos de tecnociência. Longe de permanecer a guardiã de um templo reservado, a tecnociência é um motor que traz consigo a evolução acelerada, caótica das sociedades contemporâneas. No terceiro espaço, o conhecimento não é mais fechado, trancafiado como um tesouro: insere-se em toda a parte, difunde-se, mediatiza-se, semeia em todos os lugares a inovação (LÉVY, 1994, p. 179).

Outro ponto conceitual importante em relação aos territórios digitais é que a forma de uso é fator determinante na ação de desterritorialização e reterritorialização. Lemos (2005) nos mostra que as tecnologias digitais são agentes de territo-

Rev. Estud. Comun., Curitiba, v. 15, n. 37, p. 171-184, maio/ago. 2014 
rialização e controle, assim como de desterritorialização, aumentam mobilidades e instituem formas 'nômades'. É importante destacar que as tecnologias da cibercultura, principalmente as móveis, podem criar processos desterritorializantes, mas que esta desterritorialização não está garantida pelo simples uso dos artefatos. O autor exemplifica dizendo que, apesar de um executivo estar viajando (está em mobilidade), se ele está sendo controlado pelo seu celular, ou pelo seu laptop ligado à Internet, "[...] ele está em mobilidade, mas não é um nômade, já que territorializado, controlado e controlando o fluxo de matéria e informação" (LEMOS, 2005 , p. 10). Já um internauta, por outro lado, que se tranca em seu quarto e navega por horas por informações mundiais, sem percurso pré-definido, "[...] vivencia processos nômades, desterritorializantes, sem sair do lugar" (LEMOS, 2005, p. 10). Corrêa (2002), em relação aos processos de territorialização e desterritorialização, acredita que "[...] desterritorialidade sem nova territorialidade significa exclusão do processo social" (CORRÊA, 2002, p. 253).

Para finalizar essa retomada teórica sobre territorialização, desterritorialização e reterritorialização, é preciso lembrar que, interligada com o processo de midiatização, a construção de novos territórios por meio das tecnologias não pode ser generalizada. Existem ainda povos que apesar da globalização não possuem as condições tecnológicas para saírem dos seus próprios territórios. "Mas além das redes, antes das redes, apesar das redes, depois das redes, com as redes, há o espaço banal, o espaço de todos, todo o espaço, porque as redes constituem apenas uma parte do espaço e o espaço de alguns." (SANTOS; SOUZA; SILVEIRA, 2002, p. 16). Para Neves (2002), tudo parece conduzir a uma globalização como sinônimo de homogeneização, ao mesmo tempo em que se presencia a diversidade, a fragmentação e a heterogeneidade do que foi arranjado ou idealizado nos últimos séculos.

A próxima etapa utiliza a construção do GranaBook para exemplificar e identificar os conceitos já estudados de territorialização, desterritorialização e reterritorialização e entender como estes processos acontecem.

\section{GranaBook e a construção colaborativa da informação}

GranaBook, o guia colaborativo "para sair do perrengue" tem a intenção de ajudar o público jovem, principalmente os universitários, a administrar o seu dinheiro. O guia pretende divulgar soluções criativas para situações cotidianas e dar dicas das melhores formas de usar e investir o dinheiro. O banco Itaú é o criador desta ideia.

Esta ação de relacionamento consistiu na construção do primeiro guia colaborativo de orientação financeira elaborado a partir de interações dos usuários na página do Itaú Universitários no Facebook. Esta ação gratuita ocorreu exclusivamente em ambiente de Internet, de agosto a dezembro de 2012. 
Os usuários eram estimulados a trocar experiências entre si, além de participarem de debates e enquetes, sempre abordando o tema central do GranaBook, a orientação financeira. As melhores colaborações foram selecionadas e enviadas ao especialista em consultoria financeira, Gustavo Cerbasi, que as usou para redigir o texto do guia colaborativo, citando as colaborações e autores escolhidos, os quais foram considerados coautores do guia. Foram aceitas participações que ocorreram por meio de comentários, enquetes, imagens e/ou publicações no mural da página do Itaú Universitário no Facebook. Os critérios de escolha para as publicações serem utilizadas no guia eram: adequação ao tema; originalidade; e criatividade.

Sete capítulos foram escritos com a participação de mais de trinta e seis mil internautas, são eles: “Na boa, porque falar de grana tão cedo?; A grana é curta. Como fazê-la render mais?; Dívidas não são o fim do mundo; Quem usa mais a cabeça, usa menos dinheiro; Pense grande. Sonhos existem para virar realidade; Dinheiro se multiplica quando se sabe investir; e Ficar rico é pra qualquer um?". Depois da finalização da construção do GranaBook, ele passou da rede social digital para um site.

Mais do que mostrar a construção de um guia financeiro colaborativo, o objetivo aqui é de entender como a midiatização e os conceitos de territorialização, desterritorialização e reterritorialização podem ser reconhecidos nesta ação.

A tecnologia por meio da midiatização possibilitou diversos usos de apareIhos e técnicas que mudaram a forma estática da comunicação entre emissor e receptor. A participação dos indivíduos fica clara pelo fato de que eles auxiliaram na construção do guia colaborativo. "A lógica da mídia digital, permite que pessoas antes conhecidas como espectadoras agreguem valor umas às outras, todos os dias." (SHIRKY, 2010, p. 41). Como comentado por Hjavard (2012), os meios de comunicação digitais se integraram as rotinas e os usuários se tornaram, além de espectadores, produtores de conteúdo, e segundo o autor, esta é a lógica dos meios de comunicação contemporâneos. No caso do GranaBook, a participação ocorreu guiada por uma instituição financeira que conduziu sua criação e utilizou esta estratégia para se aproximar do público jovem e conhecer suas experiências por meio de um território midiatizado. Conforme citado por Lévy (1994), os papéis dos indivíduos são redefinidos na fabricação, circulação e consumo das coisas.

Antes de existir a possibilidade de participação dos indivíduos por meio dos meios digitais surgiu um novo território, a Internet. Ela possibilitou a desterritorialização e reterritorialização de muitos dos hábitos humanos. Com ela, assiste-se à televisão, lê-se jornal, mantem-se contato com pessoas e lugares do mundo todo apenas utilizando um computador, celular ou tablet. $O$ que não quer dizer que se tenha excluído antigos usos do cotidiano, "Os velhos meios de comunicação não estão sendo substituídos. Mais propriamente, suas funções e status estão sendo transformados pela introdução de novas tecnologias" (JENKINS, 2008, p. 42).

Rev. Estud. Comun., Curitiba, v. 15, n. 37, p. 171-184, maio/ago. 2014 
Ao se pensar como seria construído um guia colaborativo há alguns anos, no mínimo, haveria dependência do encontro de várias pessoas no mesmo lugar físico para a discussão e elaboração do material, que depois se tornaria um livro impresso; sem falar nos custos para a empresa, do tempo e da disponibilidade das pessoas em participar. Mas, além disso, o mais importante é a discussão que se deu de uma forma visível ao público e que possibilitou o cruzamento de diferentes pensamentos sobre o assunto. A questão aqui é não só as mudanças físicas que ocorrem com a desterritorialização, mas também as questões comunicacionais trazidas pela reterritorialização. Sendo assim, confirma-se o pensamento de Corrêa (2002) quando ele afirma que a desterritorialização é a perda do território apropriado e vivido, pois, segundo o autor, a reterritorialização é a criação de novos territórios, seja pela reconstrução parcial ou total de antigos territórios. Isto é, pela recriação parcial ou total em um novo território mas com algumas características do antigo.

Como citado por Lemos (2005), o ciberespaço é desterritorializante, mas este procedimento não existe sem novas reterritorializações. Neste caso, o processo de globalização e midiatização a Internet desterritorializou o livro que se reterritorializou em outra ambiência, a Internet. No site do GranaBook, a principal chamada é : "Em um livro, o prefácio diz o que você pode esperar das próximas páginas, já aqui é o que você pode esperar dos próximos cliques." Santos (2006) e Lemos (2005) já afirmaram que os processos de desterritorialização existem quando os elementos fixos permitem a modificação do próprio lugar e então novos fluxos recriam as condições ambientais e sociais e o redefinem.

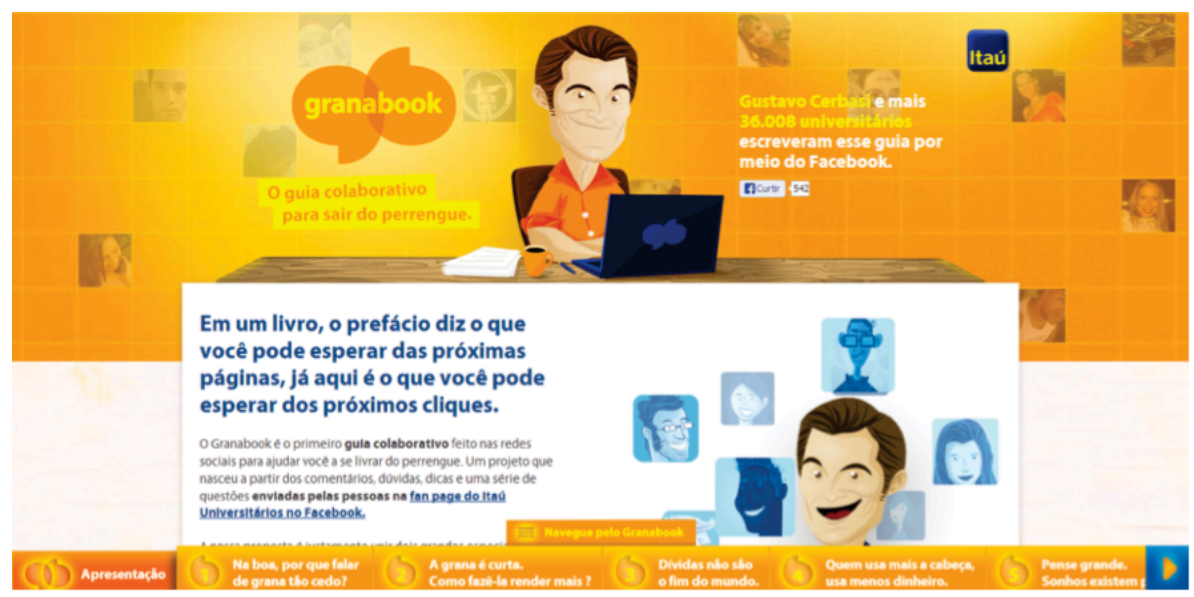

Figura 1: Página inicial do GranaBook

Fonte: www.granabook.com

O GranaBook não necessitou de expressivos investimentos do banco Itaú para ser construído. A rede social digital que foi o suporte para sua formação é 
gratuita e a participação das pessoas não era recompensada. Segundo os conceitos propostos neste estudo, o banco Itaú utilizou um território disponibilizado pela tecnologia e pela midiatização, que aproximou seus públicos de interesse, desterritorializou um livro impresso e reterritorializou-o no meio digital, trazendo informação e conhecimento da mesma maneira, mas em outra ambiência. Porém, é preciso esclarecer que estes processos não são tão simples quanto parecem. Mercadologicamente é preciso pensar estratégias direcionadas aos novos territórios digitais que estão cada vez mais segmentados e abrangentes ao mesmo tempo. Um território destinado ao público jovem, por exemplo, necessita de ações que se destaquem em meio à quantidade de informação disponibilizada pelos meios digitais e pelas outras instituições financeiras.

Junto com o encurtamento do espaço e tempo, a comunicação digital trouxe outras formas de relacionamento entre empresas e consumidores e, neste sentido, Lemos (2005) comentou que toda a mídia cria processos os quais instauram processos de territorialização e desterritorialização e que a compressão do espaço-tempo possibilita o acesso à informação e assim criam processos desterritorializantes em níveis político, econômico, social, cultural e subjetivo. Por isso, a busca por estratégias comunicacionais que se diferenciem das já utilizadas no território mercadológico ou que sejam desterritorializadas e reterritorializadas nos ambientes comunicacionais digitais.

\section{Considerações finais}

A proposta principal deste estudo foi aprofundar os conceitos de territorialização, desterritorialização e reterritorialização de forma a mostrar diferentes perspectivas de autores que refletem sobre o tema. Em um segundo momento, o objetivo foi trazer o GranaBook como exemplo para a identificação dos conceitos em análise, tornando-os visíveis num objeto advindo da midiatização.

Pode-se perceber que a midiatização, como comentada por Hjavard (2012), possibilita que a mídia e os meios digitais se aproximem de diferentes culturas e que hoje estas culturas não são construídas de forma isolada umas das outras. As relações sociais, citadas por Giddnes (1991), acontecem em escala mundial, podendo assim aproximar essas pessoas de diferentes territórios. A tecnologia aproxima e diversifica os territórios existentes, fazendo assim com que ocorra a desterritorialização e reterritorialização.

Um ponto chave que Lemos (2005) e Corrêa (2002) comentam é que não existe desterritorialização sem novas reterritorializações. Pode-se perceber isto com o exemplo do GranaBook, pois ele deixou de ser um livro impresso, se desterritorializando e se reterritorializando em uma nova ambiência.

Rev. Estud. Comun., Curitiba, v. 15, n. 37, p. 171-184, maio/ago. 2014 
Com isso, foi possível perceber que se está o tempo todo sendo expostos a desterritorializações e reterritorializações. As diversas formas de comunicação estão inclusas no cotidiano e cada vez mais mudando os hábitos e formas de as pessoas se relacionarem com o mundo.

\section{Referências}

ANDRADE, M.C de. Territorialidades, desterritorialidades, novas territorialidades: os limites do poder nacional e do poder local. In: SANTOS, M.; SOUZA, M. A. A. de; SILVEIRA, M. L. Território Globalização e Fragmentação. São Paulo: Hucitec, 2002.

BARICHELLO, E. M. R. Comunicação e Comunidade do Saber. Santa Maria: Palotti, 2001.

CORRÊA, R. L. Territorialidade e corporação: um exemplo. In: SANTOS, M.; SOUZA, M. A. A. de; SILVEIRA, M. L. Território Globalização e Fragmentação. São Paulo: Hucitec, 2002.

DELEUZE, G.; GUATTARI, F. Mil Platôs: capitalismo e esquizofrenia 2. São Paulo: Ed. 34, 1995.

FAUSTO NETO, A. Mudanças da Medusa? A enunciação midiatizada e sua incompletude In FAUSTO NETO; et. al. (Org.). Midiatização e Processos Sociais na América Latina. São Paulo: Paulus, 2008. Cap. 6, p. 119-144.

GEIGER, P. P. Des-territorialização e espacialização. In: SANTOS, M.; SOUZA, M. A. A. de; SILVEIRA, M. L. Território Globalização e Fragmentação. São Paulo: Hucitec, 2002.

GIDDENS, A. As Consequências da Modernidade. São Paulo: UNESP, 1991.

GOMES, P. G. O Processo de Midiatização da Sociedade e sua Incidência em Determinadas Práticas Sociossimbólicas na Contemporaneidade: a relação mídia e religião In FAUSTO NETO; et. al. (orgs.). Midiatização e Processos Sociais na América Latina. São Paulo: Paulus, 2008. Cap. 1, p. 17-30.

HJAVARD, S. Midiatização: teorizando a mídia como agente de mudança social e cultural. In: Revista Matrizes. São Paulo, 2012. p. 53-91.

JENKINS, H. Cultura da Convergência. São Paulo: Aleph, 2008.

LEMOS, A. Ciberespaço e Tecnologias Móveis. Processos de Territorialização e Desterritorialização na Cibercultura. Facom UFBa, 2005. Disponível em: <http://www.facom.ufba.br/ciberpesquisa/andrelemos/territorio.pdf>. Acesso em: 18 jun. 2013. 
LÉVY, P. A Inteligência Coletiva. 2ạ. ed. São Paulo: Loyola, 1999.

NEVES, G. R. Territorialidade, desterritorialidade, novas territorialidades (algumas notas). In: SANTOS, M.; SOUZA, M. A. A. de; SILVEIRA, M. L. Território Globalização e Fragmentação. São Paulo: Hucitec, 2002.

NICOLAS, D. H. Tempo, espaço e apropriação social do território: rumo à fragmentação na mundialização? In: SANTOS, M.; SOUZA, M. A. A. de; SILVEIRA, M. L. Território Globalização e Fragmentação. São Paulo: Hucitec, 2002.

ORTIZ, R. Mundialização e Cultura. São Paulo: Brasiliense, 2000.

SANTOS, M. A Natureza do Espaço: técnica e tempo, razão e emoção. São Paulo: Edusp, 2006.

SHIRKY, C. A Cultura da Participação. Rio de Janeiro: Zahar, 2011.

SODRÉ, M. Antropologia do Espelho. Petrópolis, RJ: Vozes, 2002.

SOUZA, M. A. A. de. Geografias da desigualdade: globalização e fragmentação. In: SANTOS, M.; SOUZA, M. A. A. de; SILVEIRA, M. L. Território Globalização e Fragmentação. São Paulo: Hucitec, 2002.

Fan Page Itaú Universitários: Disponível em <https://www.facebook.com/ \#!/ItauUniversitarios/app_469881813042489> . Acesso em: 20 de jun. 2013.

Site GranaBook: Disponível em <http://www.granabook.com.br/>. Acesso em: 20 de jun. 2012=3. 